\title{
Light-rearing effects on factors of mouse emotionality and endocrine organ weight
}

\author{
LEENDERT P. MOS \\ University of Alberta, Edmonton, Alberta, Canada
}

\begin{abstract}
Sixty mice from two emotionally divergent inbred strains, C57BL/10Alb and BALB/Alb, were reared in either a dark or one of two different light environments. At 50 days of age, all animals were administered a battery of tests consisting of 19 measures of emotionality. Factor scores were computed for all animals on six factors of emotionality previously obtained. At 58 days of age, all animals were dissected and pituitary, adrenal, spleen, and gonad weight recorded. Analysis of variance on the factor scores indicated strain differences on all six factors and rearing differences on four factors: Autonomic Balance, Motor Discharge, Tunneling I, and Tunneling II. Analysis of variance on organ weight measures indicated strain, sex, and rearing effects. Correlations between factors and adrenal, pituitary, and spleen weight were found for both sexes. These results, which are consistent with previous findings, suggest that light rearing affects maturation of the hypothalamicpituitary-adrenal axis and, hence, emotionality.
\end{abstract}

Environmental lighting via its influence on neuroendocrine pathways affects the activity of several hypothalamic-pituitary target organ axes in the rodent (Fiske \& Lambert, 1962; Sorrentino, Reiter, $\&$ Schalch, 1971). Both wavelength and light intensity are important variables in these experiments (Lecyk, 1962; Vriend \& Lauber, 1973). Furthermore, environmental lighting effects are both strain and age dependent, and it has been suggested that there are critical periods in the development of the hypothalamic-pituitary target organ axes (Krecek, 1971). It may be expected that the ontogeny of these axes is particularly important with respect to emotional behavior insofar as the latter has its basis in endocrine functioning. Environmental lighting may thus prove to be an interesting variable in the study of the three-way interaction of genotype, environmental input, and emotional behavior.

Environmental lighting has been manipulated within the context of studying the relative contribution of experiential factors on visually guided behavior (Riessen, 1958) and emotional behavior (Mos, Vriend, \& Poley, 1974; Tees, 1969). Adrenocortical functioning has also been related to chase, fight, attack, and grooming variables (Vale, Vale, \& Harley, 1971) and elimination and activity measures in the open-field test (Ader, 1969). Mos et al. (1974), in a factor analytic study of emotionality and endocrine measures, found that light- vs. dark-rearing

The author acknowledges J. R. Royce (Psychology) and J. K. Lauber (Zoology) for the use of their laboratory facilities, and $\mathrm{J}$. Vriend for his assistance throughout this series of studies. Requests for reprints should be sent to Leendert Mos, Center for Advanced Study in Theoretical Psychology, University of Alberta, Edmonton, Alberta, Canada T6G 2E9. affected factors of emotionality and endocrine organ weight of inbred strains of mice. The investigators suggest that light rearing accelerates maturation of the hypothalamic-pituitary-adrenal axis and hence the capacity of animals to respond to stress.

The purpose of the present study was to replicate the results and extend, via a more elaborate design, the findings reported by Mos et al. (1974). Thus the study was designed to investigate the effects of darkrearing and two different light-intensity environments (white light of $58 \mu \mathrm{Wcm} \mathrm{cm}^{2}$ and blue light of $94 \mu \mathrm{Wcm}^{2}$ ) on emotional behavior as measured by factors of emotionality and various endocrine organ weights in the BALB/Alb and C57BL/10Alb inbred mouse strains.

\section{METHOD}

\section{Subjects}

Pregnant female mice of the BALB/Alb and C57BL/10Alb strains were obtained from stock maintained by Bioscience Animal Services at the University of Alberta. These are sublines of the BALB/cJ and C57BL/10J strains originally obtained from the Jackson Laboratory. Eight and 10 litters, pruned to 5 animals each, of the BALB/Alb and C57BL/10Alb strains, respectively, were reared from birth in one of three light environments. At 21 days of age, all animals were weaned and an equal number of males and females arbitrarily selected and housed separately in groups of 5 in their respective light environments until 50 days of age, when behavioral testing began. The selection of animals was restricted so that no more than one animal per litter was assigned to each experimental group. A total of 60 animals were available at time of testing. At 58 days of age, all animals were sacrificed and the various endocrine organ weights recorded.

\section{Housing}

All animals were housed in translucent plastic breeding cages $(19 \mathrm{~cm}$ wide $\times 19 \mathrm{~cm} \mathrm{high} \times 27 \mathrm{~cm}$ long) with bedding and ad-lib food and water. Dark-reared animals were housed in plastic 
breeding cages placed inside light-tight environment chambers. The front of each chamber was supplied with a port designed to give access to the animals and to serve as a light-baffled air vent. Each chamber $(61 \mathrm{~cm}$ wide $\times 61 \mathrm{~cm}$ long $\times 41 \mathrm{~cm}$ high) contained four breeding cages. Ventilation was provided by forced air via an airline through the lid of each chamber, and temperature inside the chamber was recorded daily. Animals under $94-\mu \mathrm{Wcm}^{2}$ light intensity were reared in a similar chamber provided with a $30 \times 30 \mathrm{~cm}$ broad-band blue filter $(1 / 2$ band width of $70 \mathrm{~m} \mu$ ). Light was supplied by a 150 -W incandescent floodlamp mounted to 50 to $75 \mathrm{~cm}$ above the filter. Cupric sulphate $(50 \%$ solution, $2 \mathrm{~cm}$ deep in a Pyrex container) served as a heat filter. Animals reared under $58 \mu \mathrm{Wcm}^{2}$ were maintained in plastic breeding cages under white laboratory fluorescent light. Radiant energy intensity was measured with a spectroradiometer at animal level. All light-reared animals were reared from birth in $12 \mathrm{~L}: 12 \mathrm{D}$. Laboratory conditions, including environmental chambers, were maintained at $24^{\circ} \pm 1^{\circ} \mathrm{C}$ and a relative humidity of $55 \%$.

\section{Tests and Measures}

Five behavioral tests were administered over a 5-day period, with each test given at 9:30 a.m. and 5:30 p.m. Nineteen measures averaged over a.m. and p.m. were taken. All apparatus were derived from a previous study (Royce, Poley, \& Yeudall, 1973). The tests and measures are described in the order in which they were employed.

Open field. The open field was a flat white Masonite circle, $120 \mathrm{~cm}$ in diameter and divided by concentric circles intersected by lines radiating outwards from the center of the field. Uniform illumination was recorded at 1,400 lx. Five measures were taken: latency to leave the starting section, activity during a 120 -sec trial, penetration into the center of the field, number of boluses of defecation, presence or absence of urination.

Straightaway. The straightaway consisted of an open runway $(3.8 \mathrm{~cm}$ wide $\times 127 \mathrm{~cm}$ long) elevated $80 \mathrm{~cm}$ from the floor. The runway was divided into 13 sections. Illumination read from the surface of the runway was $215 \mathrm{~lx}$. Four measures were taken: latency to leave the starting section, activity during a 180 -sec trial, number of boluses of defecation, presence or absence of urination.

Pole. The pole consisted of a wire mesh platform and ladder, $87 \mathrm{~cm}$ high. Illumination read from the surface of the platform was $215 \mathrm{~lx}$. The animal was placed upon the platform, and the following measures recorded: latency to leave the platform, latency to descend the ladder, number of boluses of defecation, presence or absence of urination.

Cell and hole-in-wall. This apparatus consisted of two small cubicles $(7.5 \mathrm{~cm}$ wide $\times 7.5 \mathrm{~cm}$ long $\times 10 \mathrm{~cm}$ high), one with an opaque lid (dark compartment) and the other with a transparent lid (light compartment). A small door was located between these two cubicles. In the cell test, the animal was placed in the dark cubicle and given access to the illuminated side. In the hole-in-wall test, the animal was placed in the illuminated cubicle and given access to the dark side. In each test, three measures were taken: latency to emerge, number of boluses of defecation, presence or absence of urination.

Physiological measures. In addition to live body weights, organ weights of pituitary, adrenals, spleen, and gonads were recorded. Testes and adrenals were put into a $\mathbf{. 9 0 \%}$ saline solution im: mediately upon removal and then patted dry and weighed on a Roller-Smith precision balance. Pituitaries were removed from the base of the skull under a dissecting microscope after $24 \mathrm{~h}$ of fixation in Bouin's solution. Pituitaries, ovaries, and adrenals were weighed to the nearest $.01 \mathrm{mg}$ and testes to the nearest milligram. Appropriate precautions were taken to ensure reliability of organ removal and weighing procedures. A single blind procedure was employed for both behavioral and physiological testing.

\section{Procedure}

At 50 days of age, all animals were removed from their plastic breeding cages, weighed, and placed individually in wire cages
$(10 \mathrm{~cm}$ wide $\times 10 \mathrm{~cm}$ high $\times 20 \mathrm{~cm}$ long $)$ on laboratory racks under normal conditions. At 52 days of age, behavioral testing began and continued for 5 days. At 58 days of age, all animals were weighed and sacrificed by cervical dislocation, and the various organs were removed and weighed. This procedure, in which animals were arbitrarily chosen, took 2 days to complete.

\section{Design and Analysis}

Thirty animals of the BALB/Alb and C57BL/10Alb strains were maintained from birth in either a dark or one of two light environments. Therefore, the study constituted a 2 (strain) by 2 (sex) by 3 (rearing) factorial design with 12 cells and five animals per cell.

Nineteen behavioral variables capable of assessing six factors were employed. For present purposes, factors may be considered as behavioral dispositions which bring parsimony to the behavioral domain by subsuming the 19 measures under six factors. The factor structure for this study was obtained from Royce et al. (1973). Five variables load on the Motor Discharge factor: openfield latency, open-field activity, open-field penetration, straightaway latency, and straightaway activity. Three variables load on the Acrophobia factor: pole latency to leave platform, pole latency to descend, and pole defecation. Four variables load on the Tunneling I factor: pole latency to descend, cell urination, holein-wall defecation, and hole-in-wall urination. Three variables load on the Autonomic Balance factor: open-field defecation, straightaway defecation, and cell defecation. Four variables load on the Territoriality Marking factor: open-field defecation, openfield urination, straightaway urination, and pole urination. Two variables load on the Tunneling II factor: cell latency and holein-wall latency.

This factor structure was found to be empirically invariant across pure strains, F1 and F2 populations (Poley \& Royce, 1973), and selected factors have been found to be sensitive to the effects of maternal stimulation (Poley \& Royce, 1970), post-weaning stress (Mos, Royce, \& Poley, 1973), litter size (Egan \& Royce, 1973), pharmacological agents (Satinder, Royce, \& Yeudall, 1970), light rearing (Mos et al., 1974), and septal lesions (Mos, Lukaweski, \& Royce, 1976).

The regression method was used for estimating factor scores for each animal, using the formula $F=A^{1} R^{-1} Z$, where $A^{1}$ is the $\mathrm{n} \times \mathbf{M}$ factor structure matrix, $\mathrm{R}$ is the $\mathrm{n} \times \mathrm{n}$ correlation matrix, and $\mathrm{Z}$ is the $\mathrm{n} \times \mathrm{N}$ matrix of standard scores. The mean was set at 50 and the standard deviation at 10 for the factor scores. Following this, an analysis of variance for a 2 (strain) by 2 (sex) by 3 (rearing) factorial design was applied to each of the six factors. Live body weight, pituitary, and adrenal organ weights were analyzed separately from the behavioral measures, using a 2 (strain) by 2 (sex) by 3 (rearing) factorial design. Ovary and testes weight were analyzed by a 2 (strain) by 3 (rearing) factorial design.

\section{RESULTS}

\section{Behavioral Effects}

Analysis of variance results indicated strain differences (Motor Discharge, Autonomic Balance, Tunneling I, II, p < .01; Acrophobia, Territorial Marking, $p<.05$ ) on all six factors of emotionality. The BALB/Alb strain has higher factor scores on Autonomic Balance, Territorial Marking, Acrophobia, Tunneling I and II, while the C57BL/10Alb strain has higher factor scores on Motor Discharge. These results confirm the previously reported strain differences in emotionality (Mos et al., 1973, 1974). No sex main effects were found.

Light rearing main effects were evident on only 
MOTOR DISCHARGE FACTOR

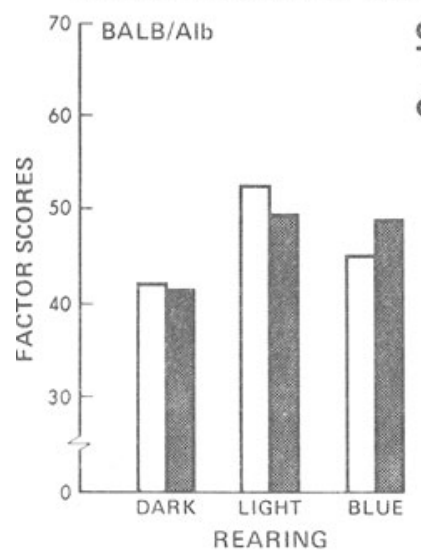

9 $\square$ C57 BL/10Alb
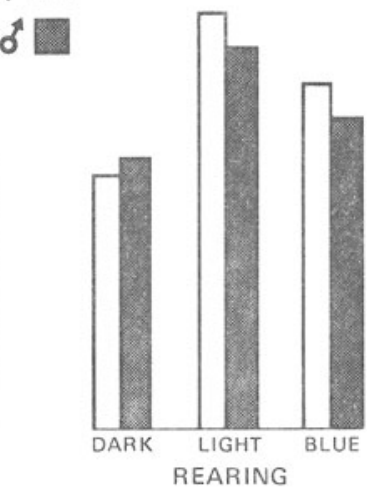

AUTONOMIC BALANCE FACTOR
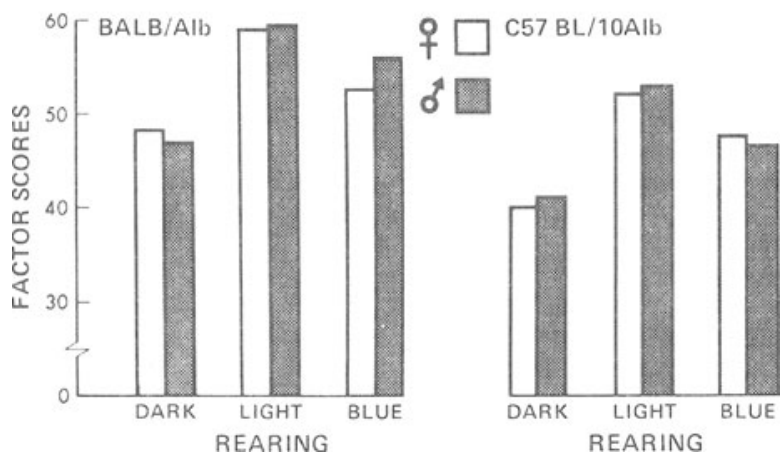

Figure 1. Strain, sex, and rearing effects on Autonomic Balance and Motor Discharge.

two factors: Motor Discharge $[\mathrm{F}(2,48)=17.15$, $\mathrm{p}<.01]$ and Autonomic Balance $[\mathrm{F}(2,48)=3.29$, $p<.05]$. The factor score pattern of both strains on these two factors were ordered for the three rearing groups: dark-rearing < (high intensity) blue lightrearing $<$ (low intensity) white light-rearing (Figure 1). These results are consistent with those previously reported for the white-light and dark-reared animals (Mos et al., 1974). In addition, the present study finds that the effects of high-intensity blue-light rearing are intermediate between dark and lowintensity white-light rearing.

In contrast to our previous study, in the present study there are two Strain-by-Light interactions on Tunneling $\mathrm{I}[\mathrm{F}(2,48)=11.86, \mathrm{p}<.01]$ and Tunneling II $[\mathrm{F}(2,48)=7.40, \mathrm{p}<.01]$. Dark- and whitelight-reared BALB/Alb animals (which have similar factor scores) have higher factor scores than highintensity blue-light-reared animals (Figure 2). Darkand high-intensity blue-light-reared C57BL/10Alb animals (which have similar factor scores) have higher factor scores than low-intensity white-lightreared animals. In comparison to the results on Autonomic Balance and Motor Discharge, darkreared BALB/Alb animals increased and white- light-reared C57BL/10Alb animals reduced their relative standing on the two Tunneling factors.

\section{Organ Weight}

Analysis of variance results of the various organ weights were highly significant (Table 1), and organ weight which is necessarily a rough measure of physiological functioning, appears fairly sensitive to the independent variables manipulated here. Analyses were based on absolute organ weight, but when they were performed on organ weight relative to body weight, the same results were obtained as reported below (Figures 3-5).

The BALB/Alb strain has heavier adrenal, spleen, ovary, testes, and body weight but lighter pituitary weight than the C57BL/10Alb strain. Females of both strains have heavier pituitary and adrenal weight; however, males of both strains have heavier body weight. A Strain by Sex interaction for adrenal weight indicates that BALB/Alb females have heavier adrenals than C57BL/10Alb females. Whitelight rearing increased spleen, adrenal, and ovary weight of both strains and pituitary weight of the C57BL/10Alb females (Light by Strain, Light by Sex) over dark-reared animals. However, white-light rearing reduced testes weight compared to dark-reared animals. These results are consistent with those previously reported (Mos et al., 1974). Higher intensity

\section{TUNNELLING ।}

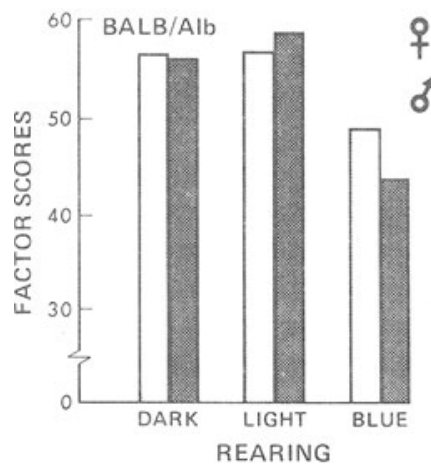

C57BL/10Alb
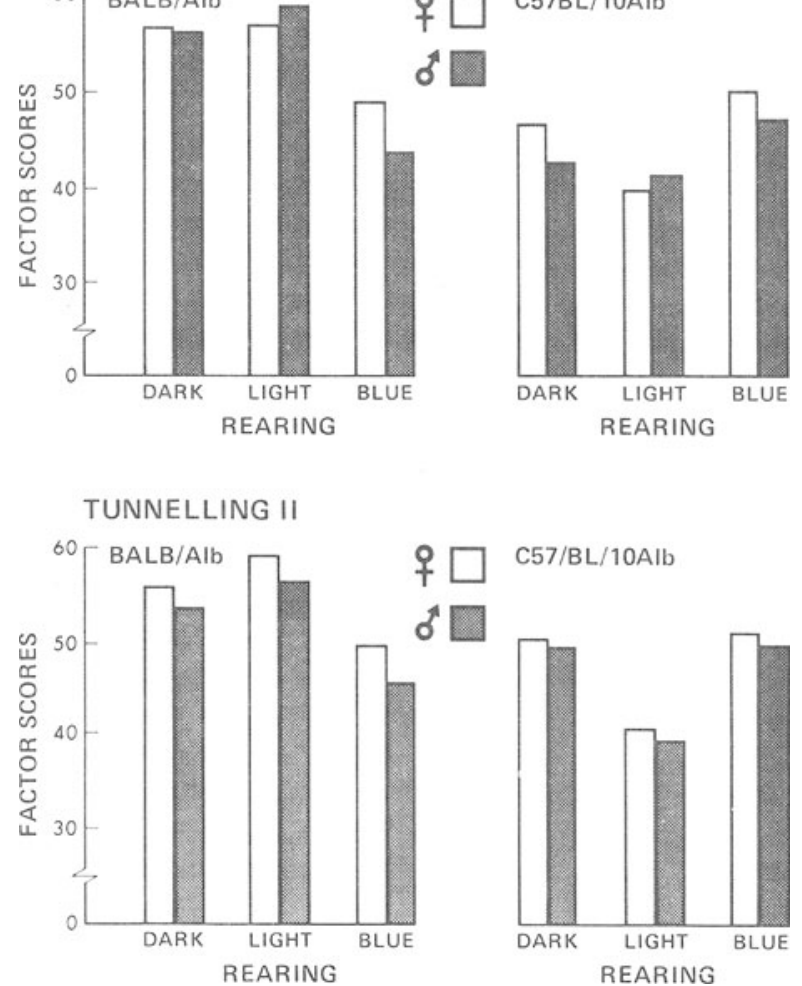

C57/BL/10Alb

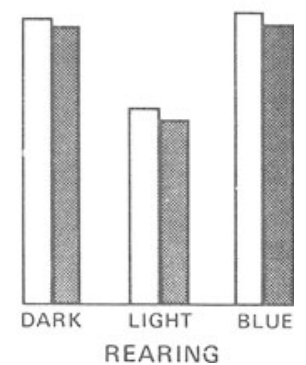

Figure 2. Strain, sex and rearing effects on Tunneling I and II. 

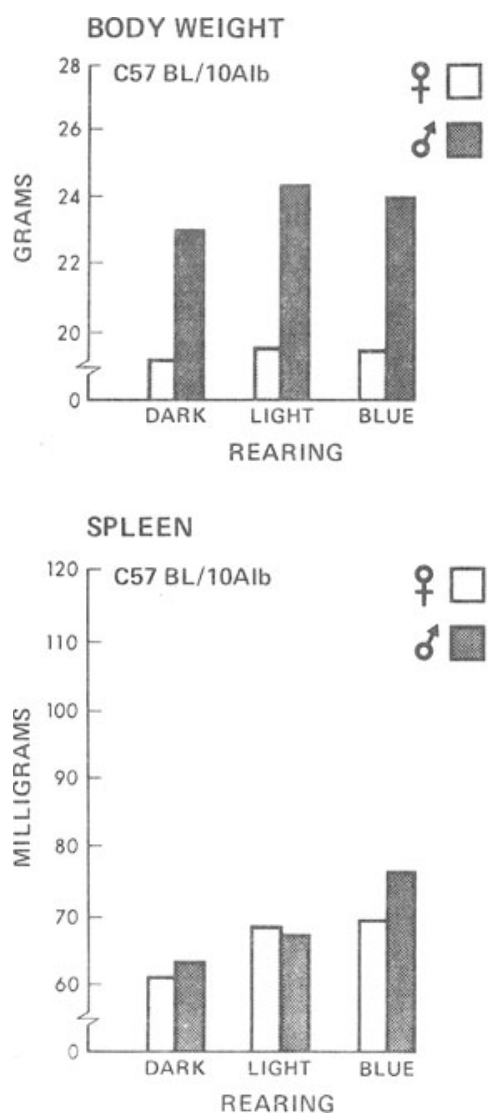

Figure 3. Strain, sex, and rearing effects on body weight and spleen weight.

blue-light rearing increased adrenal and spleen weight but reduced testes, ovary, and pituitary weight in the C57BL/10Alb strain, over both darkand white-light-reared animals. There were no rearing effects on body weight or pituitary weight of the BALB/Alb strain.

\section{Behavior and Organ Weight Correlations}

Correlations between factors and organ weight are reported in Table 2 . These correlations are computed from within-cell deviations in order to avoid the confounding effects caused by possibly inflated correlations from between-cell values. Within-cell correlations should reflect true functional relation-

ships between behavior and the various organ weights. Nevertheless, they are a conservative test of these relationships, since they do not consider between-group experimental manipulations which may genuinely affect behavior by affecting organs.

Table 2 presents the significant relationships between factors and organ weights separately for males and females. Pituitary weight is positively correlated with Motor Discharge and inversely correlated with both Tunneling factors. Adrenal weight is positively correlated with Motor Dishcarge, Acrophobia, and Autonomic Balance in females, but there are no corresponding correlations in males. Spleen weight is positively correlated with Autonomic Balance for both sexes. While these results are consistent with those previously reported (Mos et al., 1974), the pituitary weight correlations with Motor Discharge and the two Tunneling factors and the spleen weight correlations with Autonomic Balance were not found in our previous work.

\section{DISCUSSION}

It was the intent of this study to attempt to replicate our previous findings and extend their generality by including a high-intensity blue-light-rearing condition. The results confirm that light rearing affects factors of mouse emotionality, influences the development of neuro-endocrine function, and presents evidence for an interaction of light rearing, the endocrine system, and emotionality of inbred strains.

\section{Emotionality}

Strain differences on factors of emotionality are well documented (Mos et al., 1973, 1974, 1976; Poley \& Royce, 1973; Royce et al., 1973) and the present study clearly distinguishes BALB/Alb from C57BL/10Alb animals on all six factors. The present results also confirm our previous findings that lightrearing effects are primarily evident on Autonomic Balance (defecation measures) and Motor Discharge (activity and latency measures), factors which have been replicated in much of the factor analytic work investigating rodent emotionality (Denenberg, 1967; McClearn \& Meredith, 1964; Royce, 1966). In

Table 1

Analysis of Variance of (Absolute) Organ Weights

\begin{tabular}{|c|c|c|c|c|c|c|c|c|}
\hline F Table & df & $\begin{array}{c}\text { Weight } \\
\text { F }\end{array}$ & $\begin{array}{c}\text { Adrenal } \\
\text { F }\end{array}$ & $\begin{array}{c}\text { Pituitary } \\
\text { F }\end{array}$ & $\begin{array}{c}\text { Spleen } \\
\text { F }\end{array}$ & $\begin{array}{c}\text { Ovary } \\
\text { F }\end{array}$ & $\begin{array}{c}\text { Testes } \\
\text { F }\end{array}$ & df \\
\hline Light & 2 & 1.15 & $4.13^{*}$ & $5.15 * *$ & $16.06 * *$ & $11.19 * *$ & $6.24 * *$ & 2 \\
\hline Strain & 1 & $20.62 * *$ & $81.98 * *$ & $4.81^{*}$ & $108.91 * *$ & $50.20 * *$ & $7.26 * *$ & 1 \\
\hline Sex & 1 & $148.63 * *$ & $165.91 * *$ & $5.86^{*}$ & .13 & & & \\
\hline Light by Strain & 2 & 1.05 & .20 & $10.87 * *$ & $3.61 *$ & .01 & 2.90 & 2 \\
\hline Light by Sex & 2 & .97 & 3.01 & $4.20 *$ & .26 & & & \\
\hline Strain by Sex & 1 & 2.49 & $50.19 * *$ & 3.76 & .21 & & & \\
\hline Light by Strain by Sex & 2 & 1.97 & .52 & 2.20 & 2.16 & & & \\
\hline Error & 48 & 1.73 & .47 & .31 & 191.29 & 1.00 & 123.56 & 24 \\
\hline
\end{tabular}


ADRENAL WEIGHT

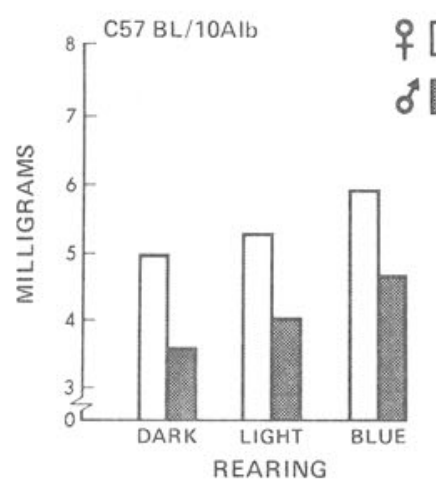

PITUITARY WEIGHT

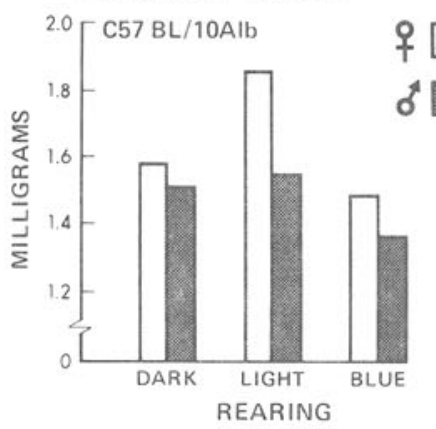

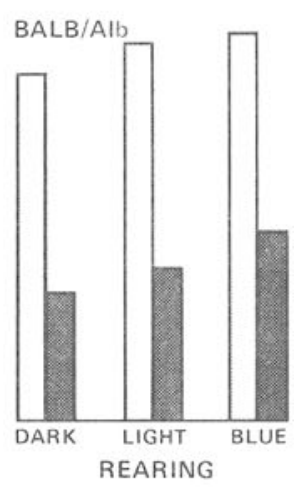

BALB/Alb

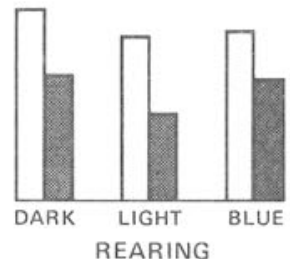

Figure 4. Strain, sex, and rearing effects on adrenal and pituitary weight.
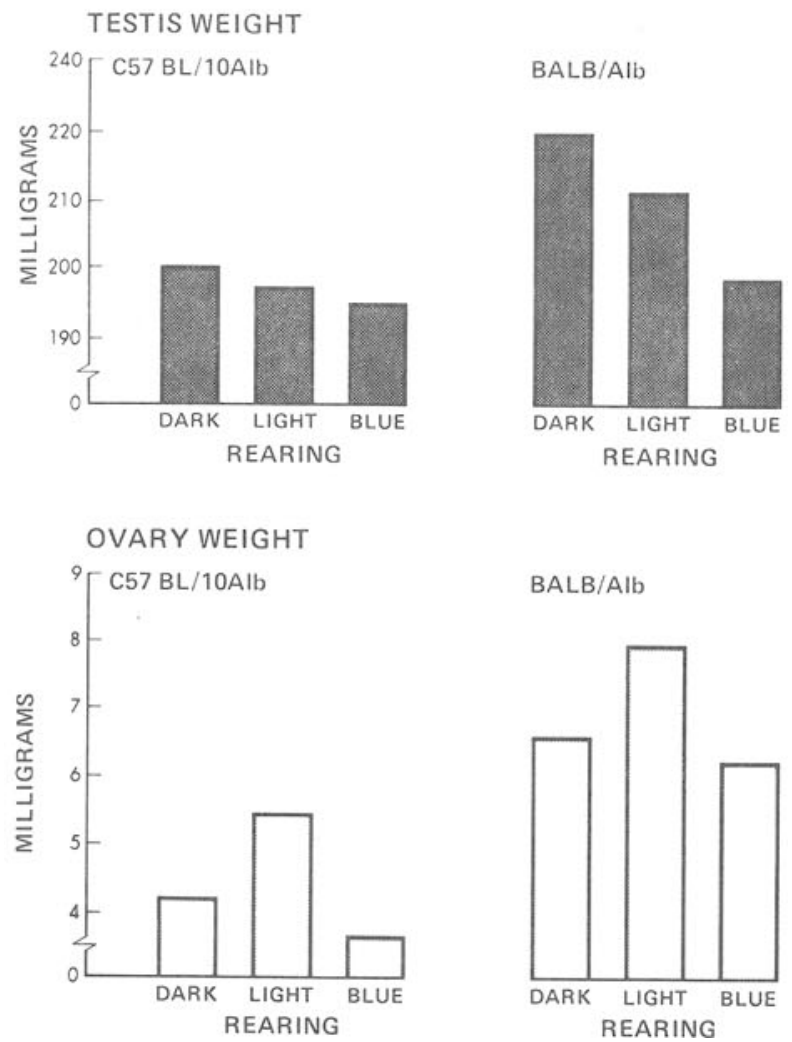

Figure 5. Strain and rearing effects on ovary and testis weight.

particular, it should be noted that, while strain differences are in the opposite direction on Autonomic Balance and Motor Discharge, rearing effects are in the same direction for both strains. This finding is quite consistent with the recently reported findings by Mos et al. (1976) that septal lesions also result in a decrement on both these factors while the two strains retain their characteristic difference in opposite directions. However, light-rearing effects are quite different for the two strains on Tunneling I and II. These Strain by Rearing interactions on the two Tunneling factors probably reflect some relative difference in task demand between Autonomic Balance and Motor Discharge (stressful), on the one hand, and Tunneling I and II (nonstressful), on the other (Mos et al., 1973). Reference to task demands in order to explain the Strain by Light interactions suggests that the two strains are at the extreme opposite ends of the two Tunneling dimensions, an assumption which is not unreasonable since the two strains were selected precisely because they were found to be emotionally divergent (Royce, Carran, \& Howarth, 1970).

With respect to light-rearing results, it is notable that, for the BALB/Alb strain, performance of high-intensity blue-light-reared animals and lowintensity white-light-reared animals remains invariant across all four factors, whereas the performance of dark-reared and high-intensity blue-light-reared animals remains invariant across all four factors for the C57BL/10Alb strain. For both strains, on all four factors, the high-intensity blue-light-reared animals showed the smallest variation in their factor scores. This finding suggests that light-rearing effects can override strain differences in emotionality and points to the importance of studying a range of

Table 2

Within-Group Correlations Between Organ and Body Weight and Factors of Emotionality

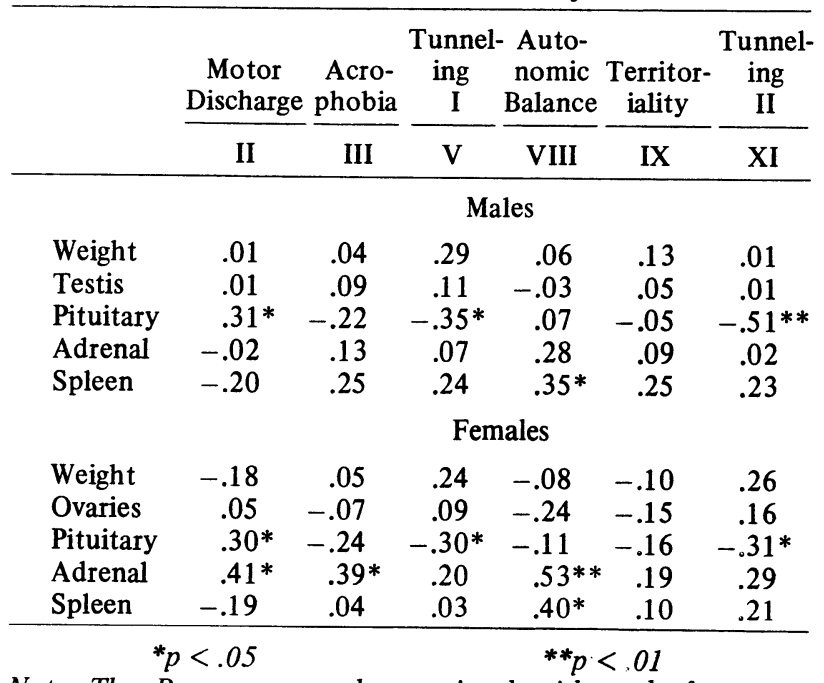

Note-The Roman numerals associated with each factor are derived from Royce, Poley, and Yeudall (1973). 
values of the light-intensity variable in relation to behavior. Dark-reared animals of the more emotionally reactive BALB/Alb strain and lowintensity white-light-reared animals of the C57BL/ 10Alb strain showed the greatest variability in their factor scores over the four factors. Dark-reared BALB/Alb increased and white-light-reared C57BL/10Alb reduced their factor scores on the two Tunneling factors compared to their results on Autonomic Balance and Motor Discharge. Thus optimal light-intensity rearing, in terms of emotional reactivity, is strain-dependent.

\section{Physiological Effects}

Strain differences in organ weight confirm our previous findings. The pituitary of the C57BL/10Alb strain normally weighs more than that of the BALB/ Alb strain (Chai \& Dickie, 1966). As modifications in testis and ovary weight are regarded as indirect indications of hormone secretion (FSH) (Flerko, 1966; Fraschini \& Martini, 1970), the strain differences in gonad weight suggest strain differences in levels of pituitary trophic hormone. Adrenal weight gives some indication of ACTH synthesis but does not reflect rapid alterations in levels of ACTH secretion (Mangili, Motta, \& Martini, 1966), nor do changes in adrenal weight always indicate increased output of adrenal steroids. However, adrenal weight may be regarded as a useful index of endocrine function modulating behavior patterns (Vale et al., 1971). Body-weight and organ-weight differences indicate strain differences in the relationship between genotype, hormone secretion, and development.

Sex differences in organ weight may represent both sex-related genetic differences in structure as well as sex differences in sensitivity of organs and tissues to hormones. Both pituitary and adrenal weight have consistently been reported to be heavier in female mice (Chai \& Dickie, 1966; Sakiz, 1960). The magnitude of this sex difference in adrenal weight is in part genetically determined, possibly due to genetic differences in sex steroids (Badr \& Spickett, 1971), which have a moderating influence on adrenal weight throughout adult life (Fiske \& Lambert, 1962; Kitay, 1961). The significant Strain by Sex interaction in the present study indicates that this sex difference is greater for the BALB/Alb than for the C57BL/ $10 \mathrm{Alb}$ strain. There are also strain and sex differences in developmental aspects of adrenal structure. The time of involution of the juxtamedullary $\mathrm{x}$ zone, for example, is both strain and sex dependent (Badr \& Spickett, 1971; Sakiz, 1960). This suggests a relationship between genotype, hormones, and development, a relationship influenced by light in both the C57BL/10Alb and BALB/Alb strains. While the present study finds no sex differences in spleen weight, both adrenal and sex steroids are known to have a moderating influence on lymphoid tissue throughout life (Dougherty, 1959). Similarly, the sex differences in body weight may be influenced by sex hormones. Dilman (1971), for example, has discussed the role of estrogen in energy homeostasis.

Light rearing may be thought of as providing a stimulus to the hypothalamic-pituitary-target organ axes. The present study confirms that light influences pituitary, adrenal, spleen, and gonad weight. This suggests that light influences the secretion of ACTH and gonadotrophic hormones in C57BL/10Alb and BALB/Alb animals and, therefore, the secretion of adrenal and sex steroids. The variation in pituitary weight due to light rearing was significantly dependent upon sex and strain, and C57BL/10Alb females appeared to be particularly sensitive in this respect. It is interesting that animals reared under the higher intensity blue light had reduced testis, ovary, and pituitary weight. Increasing intensity of the light environment of rodents appears to accelerate normal age-related pituitary-gonadal events (see Logan, 1954).

Previous studies by Brown, Pearce, and Van Allen (1926), Vriend and Lauber (1973), and Wurtman and Wiesel (1969) have pointed out that spleen weight is sensitive to the light environment of small mammals. In the present study (as in Mos et al., 1974), there were no sex differences in the spleen weight or body weight response to light, suggesting that this effect is not mediated primarily by sex or adrenal steroids. It is more likely that the spleen weight response is mediated by growth hormone or thyroxine. Growth hormone, a hormone known to be influenced by light, increases immunocompetence of thymus-derived lymphocytes in the spleen. Pierpaoli, Fabris, and Sorkin (1970) have suggested that the most critical effect of hormones, such as growth hormone and thyroxin, is during the development of the immune system. The present study provides evidence for a close interrelationship of endocrine function and growth of lymphoid tissue in inbred mice.

\section{Emotionality, Organ Weight Correlations}

As a strong test of the relationships between organ weights and emotional reactivity, we have the withingroups correlations of Table 2 . For females, greater adrenal weight is related to higher activity (Motor Discharge) and greater elimination (Autonomic Balance and Acrophobia). In males, the correlation between adrenal weight and Autonomic Balance is positive though not statistically significant. Thus, sex differences must be taken into consideration before generalizations can be made concerning endocrine-emotionality relationships. Ader (1969) has found a positive relationship between open-field activity and adrenal weight of male rats. However, on the basis of the traditional interpretation of 
open-field activity (low emotionality), he makes the strong conclusion that either open-field measures are not indicative of emotionality, or emotionality as measured in the open field is not related to adrenocortical functioning (see Stern, Erskine, \& Levine, 1973). The present study examines the relationship between emotionality measures and organ weight separately for the two sexes. It is evident that for females, at least, Autonomic Balance (elimination) and Motor Discharge (activity) are both related to measurable pituitary-adrenal function. The significant positive correlations between activity and adrenal weight appear to contradict the traditional interpretation of emotionality as related to pituitaryadrenal functioning. The traditional interpretation was put into doubt by Ader (1969), Mos et al. (1973), and Stern et al. (1973). The sex difference in the effect of adrenal functioning on behavior may be modulated by sex hormones. Kitay, Coyne, Swygert, and Gaines (1971) have found that estrogen increases the rate of secretion of adrenocortical steroids and androgen decreases the total steroid output of the adrenal.

The inverse correlations between pituitary weight and the two Tunneling factors are new to this study and deserve further investigation. However, the present findings indicate that pituitary function is related to emotional behavior and the absence of sex differences suggests that tunneling behavior is not related to pituitary-gonad or pituitary-adrenal axes but more likely is related to TSH or the growth hormone function of the pituitary. The spleen weight correlations with Autonomic Balance are more puzzling, particularly since there were no correlations between pituitary weight and Autonomic Balance.

In summary, these results confirm the photoresponsiveness of some components of the maturing endocrine system, the differential effect of light rearing on factors of emotionality, and presents evidence for interaction of environmental light intensity or wavelength, the endocrine system, and emotionality of inbred strains. Light which affects adrenal, gonadal, and thyroid secretion in young animals may affect neuroendocrine activity and emotional behavior associated with neuroendocrine regulation of pituitary-target organ axes in the adult. It is submitted that maturation of emotionality depends on maturation of endocrine (pituitary-target organ) axes. This hypothesis is probably best examined in a parallel study (controlling light conditions for intensity and wavelength or quantum energy) of hormone levels and emotionality measures at successive stages of development.

\section{REFERENCES}

ADER, R. Adrenocortical function and the measurement of "emotionality." Annals of the New York Academy of Sciences, 1969, 159, 791-805.
BADR, F. M., \& SPICKETT, S. G. Genetic variation in adrenal weight in young adult mice. Journal of Endocrinology, 1971, 49, 105-111.

Brown, W. H., Pearce, L., \& Van Allen, C. M. The occurrence and trend of spontaneous variations in organ weights of normal rabbits. Journal of Experimental Medicine, 1926, 44, 653-666.

ChaI, C., \& Dickie, M. Endocrine variations. In E. L. Green (Ed.), Biology of the laboratory mouse. New York: McGraw-Hill, 1966. Pp. 387-403.

DENENBERG, V. H. Stimulation in infancy, emotional reactivity, and exploratory behavior. In D. C. Glass (Ed.), Neurophysiology and emotion. New York: Rockefeller University Press and Russell Sage Foundation, 1967. Pp. 161-190.

Dilman, V. M. Age-associated elevation of hypothalamic threshold to feedback control, and its role in development, ageing and disease. The Lancet, 1971, 1, 1211-1219.

Dougherty, T. F. Adrenal cortical control of lymphatic tissue mass. In F. Stohlman (Ed.), The kinetics of cellular proliferation. New York: Grune, 1959. Pp. 264-277.

EgAN, O., \& Royce, J. R. Littersize and emotionality in two strains of mice. Journal of Comparative and Physiological Psychology, 1973, 82, 55-59.

Fiske, V. M., \& LAMBERT, H. H. Effect of light on the weight of the adrenal in the rat. Endocrinology, 1962, 71, 667-668.

FLERKo, B. Control of gonadotropin secretion in the female. In L. Martini \& W. F. Ganong (Eds.), Neuroendocrinology (Vol. 1). New York: Academic Press, 1966. Pp. 613-668.

Fraschini, F., \& MARTINI, L. Rhythmic phenomena and pineal principles. In L. Martini, M. Motta, \& F. Frascini (Eds.), The hypothalamus. New York: Academic Press, 1970. Pp. 529-549.

KITAY, J. T. Sex differences in adrenal cortical secretion in the rat. Endocrinology, 1961, 68, 818-824.

Kitay, J. T., Coyne, M. D., Swygert, N. H., \& Gaines, K. E. Effects of gonadal hormones and ACTH on the nature and rates of secretion of adrenocortical steroids in the rat. Endocrinology, 1971, 89, 565-570.

KRECEK, J. The theory of critical developmental periods and postnatal development of endocrine functions. In E. Tobach, L. B. Aronson, \& E. Shaw (Eds.), The biopsychology of development. New York: Academic Press, 1971. Pp. 233-248.

LECYK, M. The dependence of breeding in the field vole (Microtus arvalis) (Pall.) on light intensity and wave-length. Zoologica Poloniae, 1962, 12, 255-268.

LoGAN, E. R. Influence of environmental lighting conditions on the estrous cycle of the rat. Unpublished PhD thesis, Northwestern University, 1954.

Mangili, G., Motta, M., \& Martini, L. Control of adrenocorticotropic hormone secretion. In L. Martini \& W. F. Ganong (Eds.), Neuroendocrinology (Vol. 1). New York: Academic Press, 1966. Pp. 297-370.

McClearn, G. E., \& Meredith, W. Dimensional analysis of activity and elimination in a genetically heterogeneous group of mice (Mus musculus). Animal Behaviour, 1964, 12, 1-10.

Mos, L. P., RoyCE, J. R., \& Poley, W. The effect of postweaning stimulation on factors of mouse emotionality. Developmental Psychology, 1973, 8, 229-239.

Mos, L. P., VRIEnd, J., \& Poley, W. Effects of light environment on emotionality and the endocrine system of inbred mice. Physiology and Behavior, 1974, 12, 981-989.

Mos, L. P., Lukaweski, R., \& Royce, J. R. Effects of septal lesions on factors of mouse emotionality. Journal of Comparative and Physiological Psychology, 1976, in press.

Pierpaoli, W., Fabris, N., \& Sorkin, E. Developmental hormones and immunological maturation. In G. E. W. Wolstenholme \& J. Knight (Eds.), Hormones and the immune response. Edinburgh: Churchill Livingstone, 1970. Pp. 126-153.

Poley, W., \& Royce, J. R. Genotype, maternal stimulation, and factors of mouse emotionality. Journal of Comparative and Physiological Psychology, 1970, 71, 246-250.

Poley, W., \& RoYCE, J. R. Behavior-genetic analysis of mouse emotionality, II: Stability of factors across genotypes. Animal Learning \& Behavior, 1973, 2, 116-120. 
Riessen, A. H. Plasticity of behavior: Psychological aspects. In H. F. Harlow \& C. N. Woolsey (Eds.), Biological and biochemical bases of behavior. Madison, Wis: University of Wisconsin, 1958. Pp. 425-450.

RoYCE, J. R. Concepts generated in comparative and physiological psychological observations. In R. B. Cattell (Ed.), Handbook of multivariate experimental psychology. Chicago: Rand McNally, 1966. Pp. 642-683.

Royce, J. R., CARran, A., \& Howarth, E. Factor analysis of emotionality in ten inbred strains of mice. Multivariate Behavioral Research, 1970, 5, 19-48.

Royce, J. R. Poley, W., \& Yeudall, L. T. Behavior-genetic analysis of mouse emotionality. Journal of Comparative and Physiological Psychology, 1973, 83, 36-47.

SAKIz, E. Etude fonctionelle de l'influence des gonades sur la corticosurrenale. Compte Rendu Société de Biologie, 1960, 154, 1159-1163.

Satinder, K. P., Royce, J. R., \& Yeudall, L. Effects of electric shock, d-amphetamine sulphate, and chlorpromazine on factor of emotionality in inbred strains of mice. Journal of Comparative and Physiological Psychology, 1970, 71, 443-474.

Sorrentino, S., Jr., Reiter, R. J., \& Schalch, D. S. Inter- actions of the pineal gland, blinding and underfeeding on reproductive organ size and ratio-immunoassayable growth hormone. Neuroendocrinology, 1971, 1, 105-115.

Stern, J. M., Erskine, M. S., \& Levine, S. Dissociation of openfield behavior and pituitary-adrenal function. Hormones and Behavior, 1973, 4, 149-162.

TEEs, R. C. Effect of early visual restriction on subsequent activity and emotionality in the rat. Journal of Genetic Psychology, 1969, 114, 193-202.

VALE, J. R., VALE, C. A., \& HARLEY, J. P. Interaction of genotype and population number with regard to aggressive behavior, social grooming, and adrenal and gonadal weight in male mice. Communications in Behavioral Biology, 1971, 6, 209-221.

VRIEND, J., \& LAUBER, J. K. Light intensity, wavelength and quantum effects on gonads and spleen of the Deer Mouse. Nature, London, 1973, 244, 37-39.

Wurtman, R. J., \& Weisel, J. Environmental lighting and neuroendocrine function: Relationship between spectrum of light source and gonadal growth. Endocrinology, 1969, 85, 1218-1221.

(Received for publication June 14, 1976; revision accepted September 7, 1976.) 